\title{
Quantification of Oil Fractions of Deep-Fried Wheat Dough and Batter Enriched with Oat and Wheat Bran
}

\author{
Oluwatoyin O. Onipe $\mathbb{D}^{1},{ }^{1}$ Daniso Beswa $\mathbb{D}^{2},{ }^{2}$ and Afam I.O. Jideani $\mathbb{D}{ }^{1,3}$ \\ ${ }^{1}$ Department of Food Science and Technology, Faculty of Science Engineering \& Agriculture, University of Venda, \\ Thohoyandou 0950, South Africa \\ ${ }^{2}$ Department of Biotechnology and Food Technology, University of Johannesburg, Doornfontein, Johannesburg 2028, South Africa \\ ${ }^{3}$ Postharvest-Handling Group, ISEKI-Food Association, Vienna, Austria \\ Correspondence should be addressed to Oluwatoyin O. Onipe; 14004637@mvula.univen.ac.za
}

Received 2 March 2021; Revised 15 August 2021; Accepted 24 August 2021; Published 31 August 2021

Academic Editor: Yan Zhang

Copyright (C) 2021 Oluwatoyin O. Onipe et al. This is an open access article distributed under the Creative Commons Attribution License, which permits unrestricted use, distribution, and reproduction in any medium, provided the original work is properly cited.

\begin{abstract}
This study investigated oil distribution in two types of deep-fried dough products with two moisture levels (65 and 100 wt. \%), two bran types (oat and wheat bran), and five bran concentrations (5-20\%). The total oil content of fried products was categorised as surface oil (SO), penetrated surface oil (PSO), and structural oil (STO) using a spectrophotometric method. Moisture loss reduced $(p<0.05)$ from $23.35 \%$ in the control to $15.19 \%$ fried batter (FB) and to $20 \%$ oat bran (OB), while a reverse trend was observed in the fried dough. Reduction of total oil from $0.43 \mathrm{~g} / \mathrm{g}$ in the control to $0.38 \mathrm{~g} / \mathrm{g}$ at $20 \% \mathrm{OB}$ and $8 \%$ wheat bran (WB) was observed. At $15 \% \mathrm{OB}$ and $20 \% \mathrm{WB}$, total fat reduced from $0.41 \mathrm{~g} / \mathrm{g}$ in the control to $0.26 \mathrm{~g} / \mathrm{g}$ of fried dough (FD). The trend STO $<\mathrm{SO}<\mathrm{PSO}$ was observed in FD, while FB followed a $\mathrm{SO}<\mathrm{STO}<\mathrm{PSO}$ trend. This investigation indicated that oil uptake reduction in fried dough products is achievable through ingredient modifications. The method of oil distribution measurement used herein can be applied to other thick deep-fried food systems in the assessment of product quality.
\end{abstract}

\section{Introduction}

Fried foods are popular worldwide because of their palatability owing to the flavour imparted by fats and oils in foods. Deep frying is a popular heat and mass transfer unit operation which entails immersion of food in hot oil at high temperatures $\left(160-200^{\circ} \mathrm{C}\right)$ under atmospheric conditions, thus yielding processed foods with unique textures and rich flavours [1]. The transfer of heat from oil to food gives rise to various chemical reactions which cause cellular and subcellular changes such as starch gelatinisation, crust formation, protein denaturation, moisture loss, oil uptake, and colour and flavour development. Mass transfer is explained as the evaporation of moisture from food during frying, which creates crevices or pathways in food for oil uptake first in the crust and then gradually to the crumb [2]. This makes oil uptake reduction, modelling, and distribution important quality parameters in fried foods. The reduction of the lipid content in fried foods is required mainly because it positively correlates with diabesity and coronary diseases [3].

Based on different oil absorption mechanisms, oil fractions in fried foods can be categorised based on their location: surface, penetrated surface, and structural oil. Surface oil (SO), which represents the oil fraction that remains on the food surface after removal from the frying medium, is governed by the relationship between capillary forces and interfacial tension which causes the adsorption of oil to food $[4,5]$. Structural oil is absorbed into the core of food through crevices caused by a continuous replacement of moisture by fat during frying [6]. Penetrated surface oil (PSO), located in the crust of food, is oil suctioned into food at the cooling stage through a vacuum effect caused by the condensation of steam $[7,8]$. PSO is regarded as the most important of the three fractions because it contributes the most to the total oil uptake and is greatly influenced by the structural integrity, surface roughness, and permeability of 
the food crust [2]. An integral constituent of wheat flour dough is water, needed for hydration and activation of the gluten network; to achieve this, the right amount of water is needed [9]. Moreover, water determines the texture and volume expansion of the product because of water vapour which is unable to escape from the food core into the surrounding medium. As regards frying, one of the known mechanisms is a water-oil replacement, which states that the amount of oil lost is directly proportional to the initial water content of the fried product [10]. However, the process of moisture loss and oil uptake is asynchronous given that moisture loss occurs during the frying process and oil uptake during the cooling period [1].

Wheat bran (WB) and oat bran (OB) are low-cost fibre sources for food product development. Their benefits, attributed to insoluble and soluble fibre contents and nutrient load, include calorific reduction of foods, weight modulation, improvement of gut health, increased intestinal transit time $[11,12]$, and oil uptake reduction in fried dough [13-16]. The effect of bran inclusion on oil uptake reduction in fried dough foods is associated with ingredient formulations based on the following mechanisms: (a) increased viscosity of the food matrix [17], (b) water retention augmentation [13], and (c) barrierforming properties $[14,18]$. Oil reduction effects of WB in fried foods are limited to $\leq 20 \%$ substitution, while those of $\mathrm{OB}$ are up to $11 \%$. At higher amounts, WB increased oil absorption due to the dilution of the gluten network by coarse WB. Hence, it is recommended to reduce the particle size of bran to dimensions close to flour particles [19]. In this study, WB and OB were pulverised to $200 \mu \mathrm{m}$ size.

The product investigated in this paper is called magwinya/vetkoek, a deep-fried dough common to the Southern Africa region, and it is similar to Belgian oliebollen. In recent studies, oil uptake reduction attempts on magwinya were conducted using mixtures of wheat flour and oat bran, psyllium husk fibre [20], guar gum (unpublished), and WB of varying particle sizes $[16,21]$. Most studies on oil distribution in fried foods focused on potato products $[7,8,22]$ and one study on surface oil of the fried wheat dough model [23]. To the best of our knowledge, this present work is the first study on oil distribution in these fried products (magwinya). Therefore, the objective of this study was to quantify the oil fractions (SO, PSO, and STO) in cereal fried snacks with different moisture levels and cereal bran $(\mathrm{OB}$ and WB).

\section{Materials and Methods}

\subsection{Sample Preparation}

2.1.1. Materials. Jungle oat bran (OB), wheat bran (WB), and wheat flour (SASKO, South Africa) were sourced from local grocery shops in South Africa. Sudan III (A18318, Alfa Aesar, England) and petroleum ether $\left(40^{\circ} \mathrm{C}-60^{\circ} \mathrm{C}\right)$ were of analytical grade. Coarse $\mathrm{WB}$ and $\mathrm{OB}$ were milled using an ultracentrifugal mill (Retsch ZM 200, Haan, Germany) fitted with a $200 \mu \mathrm{m}$ sieve. Milled bran was transferred into air- tight polyethylene bags and stored at $3^{\circ} \mathrm{C}$ until further use. Bran was partially substituted with wheat flour at 5, 10, 15, and $20 \%$ to produce the fried products.

2.1.2. Production of Deep-Fried Products. The method described by Kwinda et al. [20] was used for the preparation of fried batter and dough with slight modifications. Dry ingredients (bran-wheat flour, sugar-15g, salt- $1 \mathrm{~g}$, and yeast$1 \mathrm{~g})$ were weighed, and water $(65-100 \mathrm{ml})$ was added until the ingredients are homogeneously mixed to form a dough and batter, respectively (Figure 1). The dough was kneaded in a mixer (Russell Hobbs RHSB237, South Africa) for $10 \mathrm{~min}$ and cut into $50 \mathrm{~g}$ mass and formed into a ball. The dough and batter were fermented at $30^{\circ} \mathrm{C}$ and fried at $180^{\circ} \mathrm{C}$ for a total of $5 \mathrm{~min}$ (dyed and nondyed oil) in a deep fryer (Russell Hobbs RDF300, South Africa) with an in-built automatic temperature and time control system. Oil was preheated for $1 \mathrm{~h}$ before frying commenced and discarded after $3 \mathrm{~h}$ of frying to minimise thermal degradation of oil. For each experimental run, four replicates of batter and dough were deep-fried.

\subsubsection{Preparation of the Indicator Oil Bath Dyed with Sudan} III. Approximately $1 \mathrm{~g}$ Sudan III (A18318, Alfa Aesar, England) was weighed into a volumetric flask. About $100 \mathrm{ml}$ sunflower oil was added and agitated to partially dissolve the dye and thereafter made up to $1 \mathrm{~L}$ mark. The volumetric flask containing the dye solution was transferred to a heating stirrer plate at $30^{\circ} \mathrm{C}$ for $24 \mathrm{~h}$ until complete dissolution. A dyed oil bath was prepared by adding $233 \mathrm{ml}$ of indicator oil to $3.5 \mathrm{~L}$ oil [8].

2.1.4. Frying Process. Frying was conducted in two stages according to the method of Ouchon et al. [8] with slight modifications: (i) samples were fried in plain (nondyed) oil for $4 \mathrm{~min} 40 \mathrm{sec}$ before transfer to dyed oil for the remaining $20 \mathrm{sec}$. Samples were removed from the fryer, drained, cooled for $30 \mathrm{~min}$, and weighed $[7,8]$. Four samples were fried for each experimental run. The dough-to-oil ratio was kept at $1: 23$ by volume to avoid drastic fluctuations in frying temperature [24]. Temperature gradients in the oil bath were maintained by constantly stirring while flipping the samples every $30 \mathrm{sec}$. Frying time and temperature of $5 \mathrm{~min}$ and $180^{\circ} \mathrm{C}$ were chosen as the optimum frying time and temperature as predetermined from preliminary experiments. The choice of $20 \mathrm{sec}$ in dyed oil was made for three reasons: (i) this study was designed following the method of Ouchon et al. [8] where potato cylinders were introduced to dyed oil at about $20 \mathrm{sec}$ to the end of frying. (ii) We assumed that $20 \mathrm{sec}$ will have the most significant effect based on the study of Ufheil and Escher [7] where the product was interchangeably fried in plain and dyed oil from 0 sec to $120 \mathrm{sec}$. (iii) At a total of $5 \mathrm{~min}(300 \mathrm{sec})$ frying time, the ratio of time spent in plain versus dyed oil in our study was 14:1 (sec) which is low compared to the time ratio in the study of Ufheil and Escher [7] and similar to the time in the study of Ouchon et al. [8]. It is on the above premises that $20 \mathrm{sec}$ was 


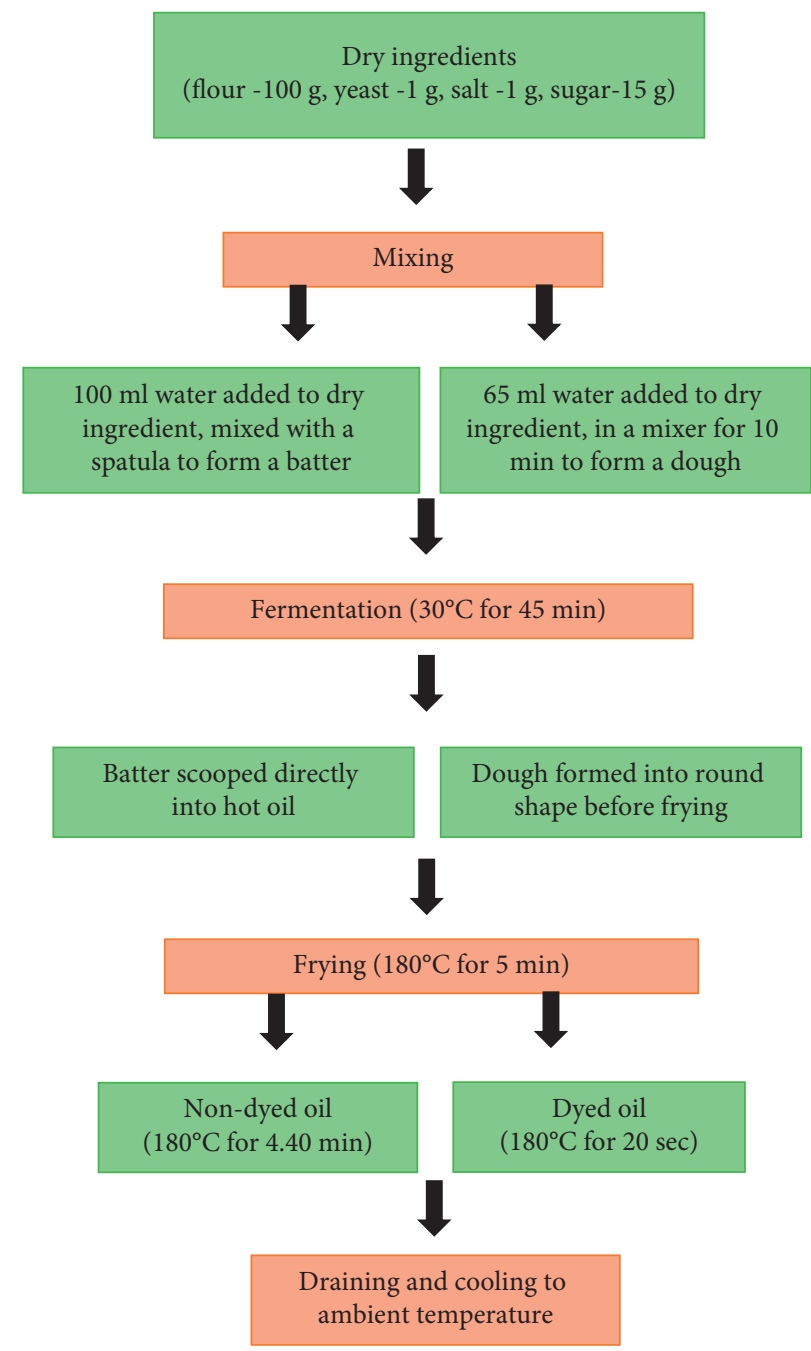

Figure 1: Flowchart for the production of fried products.

chosen. Since the purpose of this study was to quantify various oil fractions in magwinya, we did not focus on the optimisation of time in plain and dyed oil during frying. We, however, recommend further studies on time variation in the frying of our products (plain versus dyed oil).

\subsubsection{Standard Curve for the Determination of Sudan III} Concentration in Frying Oil. Solutions of different concentrations $(0.2,0.4,0.6,0.8,1.0$, and $1.2 \mathrm{mg} / \mathrm{ml})$ of Sudan III (A18318 Alfa Aesar, England) in sunflower oil were prepared as explained earlier. Each solution was diluted at 1:10 with petroleum ether $\left(40^{\circ} \mathrm{C}\right.$ to $\left.60^{\circ} \mathrm{C}\right)$ (Sigma-Aldrich), and the absorbance was measured at $509.6 \mathrm{~nm}$ with a spectrophotometer (Biowave II, Biochrom Ltd., Cambridge, England) at ambient temperature. The standard curve of concentration versus absorbance was obtained.
2.2. Weight of Fried Products. Two sets of weights were collected using a digital weighing balance: (i) fresh weight of cooled samples and (ii) weight after washing with petroleum ether-this was used in the calculation of surface oil (SO).

2.3. Moisture Loss Determination. Moisture content was determined using the approved AACC method 44-15 [25]. Magwinya samples were thinly sliced into a preweighed moisture dish and dried in an OTE80 forced-air oven (Prolab Instruments, Reinach, Switzerland) at $105^{\circ} \mathrm{C}$ for $24 \mathrm{~h}$. Dried samples were transferred to a desiccator to cool. Moisture contents of dough and batter were determined, and moisture loss was calculated using the following equation [26]:

$$
\text { moisture loss }(\%)=\frac{\text { moisture content of dough }- \text { moisture content of fried dough }}{\text { moisture content of dough }} \times 100 \text {. }
$$


2.4. Surface Oil. Surface oil (SO) was quantified using the method of Ouchon et al. [8] with modifications. SO was determined by washing each sample with $50 \mathrm{ml}$ petroleum ether for $2 \mathrm{~s}$ into a clean preweighed $250 \mathrm{~mL}$ beaker. SO was collected through gentle evaporation of petroleum ether. The flask containing extracted oil was dried to a constant mass by heating at $105^{\circ} \mathrm{C}$ in an OTE80 forced-air oven (Prolab Instruments, Reinach, Switzerland). Percentage of SO was calculated using the following equation:

$$
\operatorname{surface} \text { oil }(\%)=\frac{W_{i}}{W_{i}+W_{m}},
$$

where $W_{i}$ is the weight of oil (g) in the beaker and $W_{m}$ is the weight of the sample after washing with ether.

2.5. Penetrated Surface Oil and Structural Oil. After washing with petroleum ether, the samples were finely cut and dried for $24 \mathrm{~h}$ at $60^{\circ} \mathrm{C}$. Subsequently, the dried samples were pulverised in a grinder, and $5 \mathrm{~g}$ of the ground sample was transferred into $25 \times 80 \times 1.5 \mathrm{~mm}$ cellulose extraction thimbles (Whatman Intl. Ltd., Maidstone, UK). Fat extraction was conducted using an automated Soxhlet machine based on AACC method 30-25.01 [25]. Soxhlet-extracted oil was diluted with petroleum ether at ratio $1: 10$, and the absorbance was measured at $509.6 \mathrm{~nm}$ using a spectrophotometer (Biowave II, Biochrom Ltd., Cambridge, England) against the standard curve obtained from the standards. PSO was calculated using equation (3). Dyed oil corresponds to oil absorbed at the end of the frying process and has penetrated the structure of the product during cooling, that is, PSO. The structural oil and total oil contents were calculated from equations (4) and (5) [8].

$$
\begin{aligned}
& \text { PSO }(\mathrm{g})=\frac{\text { Soxhlet }- \text { extracted oil }(\mathrm{g}) \times \text { dye concentration in extracted oil }(\mathrm{g} / \mathrm{l})}{\text { dye concentration in the oil bath }(\mathrm{g} / \mathrm{l})}, \\
& \text { STO }(\mathrm{g})=\text { Soxhlet }- \text { extracted oil }(\mathrm{g})-\text { PSO }(\mathrm{g}) \\
& \text { total oil }(\mathrm{g} / \mathrm{g})=\text { SO }(\mathrm{g})+\text { PSO }(\mathrm{g})+\text { STO }(\mathrm{g})
\end{aligned}
$$

2.6. Statistical Analysis. Frying experiments and analyses were conducted in four replicates. Multivariate linear regression was used to test the main and interaction effect of factors (amount of bran and water addition) on the dependent variables. Analysis of variance using Duncan's multiple range test was used to separate means $(p<0.05)$. Association between responses was determined using Pearson's correlation test [16].

\section{Results and Discussion}

3.1. Moisture Loss of Cereal Fried Products. Moisture loss corresponds to the amount of water lost due to frying, while moisture content is the available moisture in food which can be expressed on a wet or dry basis [27]. In general, the moisture values for fried batter were higher than those for fried dough primarily because of the lower initial water content in the dough formulation. Moisture loss of oat bran fried batter (OBFB) samples ranged significantly $(p<0.05)$ from 15.19 to $22.34 \%$ with the highest value in OB20. There was no significant change in the moisture loss in OB5 and OB10; nonetheless, a significant increase was observed in OB15 and OB20 (Figure 2(a)). Control had the least amount of moisture retained in food at the end of the frying process.

$\mathrm{OB}$ significantly enabled moisture retention in food which is a characteristic favoured by magwinya consumers. Interestingly, a different trend was observed for oat bran fried dough (OBFD) in terms of moisture retention and loss. Mean moisture loss ranged from 14.21 to $17.66 \%$ in OBFD. The control sample was significantly lower, and OBD20 was markedly higher $(p<0.05)$ than the rest of the samples. In terms of moisture retained in the product, control had the highest moisture content of $34.54 \%$, and it was not significantly different from the sample with $10 \%$ OB.

Moisture loss in wheat bran fried batter (WBFB) samples ranged from 18.69 to $23.36 \%$, followed a significant $(p<0.05)$ upward trend from 5 to $20 \%$ WB addition (Figure 2(b)), and had no difference, meaning that WB had a marked negative effect on moisture loss of fried samples. This may be attributed to the increased water holding capacity of WB because of more binding sites in the smaller particle size [28]. Moisture loss in wheat bran fried dough (WBFD) samples ranged from 11.79 to $14.21 \%$, and a downward significant trend $(p<0.05)$ was observed in moisture loss. This implies that WB allows the retention of moisture in a low-water dough system. Water is an important ingredient in a dough matrix because it is needed for the hydration of starch molecules, thereby impacting the texture of the final product. Besides, water influences the volume expansion of the fried product through the process of water vaporisation, crust pore formation, and structural integrity of the fried product [29]. In a dough system, free water is lost first from the product in the first few seconds of frying. The variation in the moisture losses reported in this study can be explained by the interaction between the binding sites on bran and water molecules [19], which reduced the amount of free water lost during deep frying.

3.2. Surface Oil Content of Fried Products. Surface oil (SO) is oil that adheres to the food surface after removal from frying oil [8], and it is equally referred to as adhered oil [23]. The 


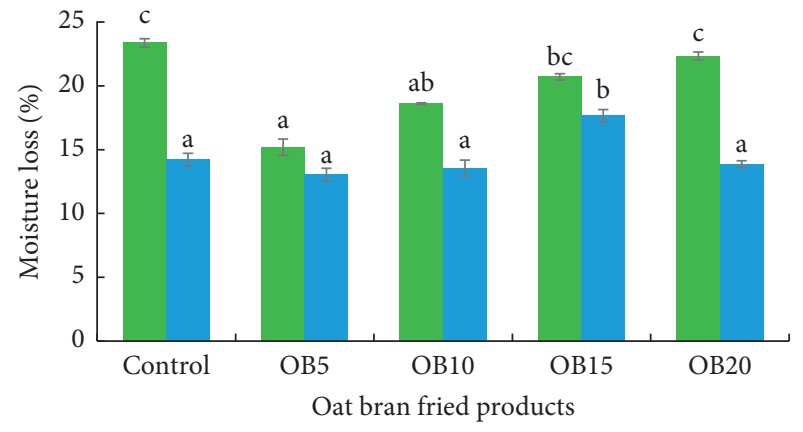

- Fried batter

- Fried dough

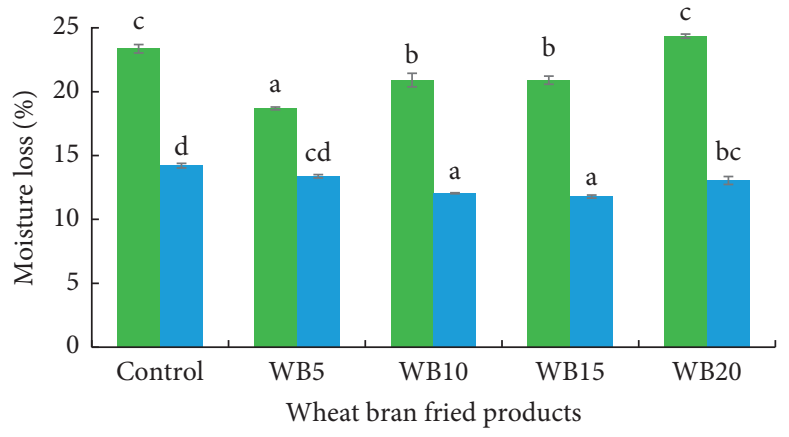

- Fried batter

- Fried dough

(a)

(b)

Figure 2: Moisture loss of (a) oat bran (OB) and (b) wheat bran (WB) fried snacks' dough and batter samples. Values are the mean of four replicates. The error bar signifies standard deviation $(\leq 1.50)$. The same bars with different superscripts showed significance $(p<0.05)$ using Duncan's multiple range test.

amount of oil absorbed into food during the cooling stage is largely dependent on oil present on the food surface after the removal of frying oil. The $\mathrm{SO}$ values of $\mathrm{WB}$ samples are presented in Figure 3(a). SO of WBFB with 5 and 20\% showed a significant increase $(p<0.05)$ from the control, and other samples showed no difference. Similarly, in WBFD (Figure 3(b)) samples, all samples showed a significant decrease $(p<0.05)$ from the control, except WB10. There was no marked difference $(p<0.05)$ between SO of control and $\mathrm{OB}$ samples; however, there were differences amongst the samples (Figure 3(c)). However, the inclusion of $\mathrm{OB}$ in fried dough significantly reduced $(p<0.05)$ SO compared to the control (Figure 3(d)). Generally, fried dough showed higher SO than fried batter. Additionally, SO was higher in WB samples than in OB samples. This may be because of the insoluble nature of $\mathrm{WB}$ fibres present which reduced moisture retention and caused rapid crust formation, thus slowing down the movement of oil into the product. Multivariate linear regression revealed that bran addition, product formulation, and interaction effect of both factors all had a significant effect $(p<0.05)$ on surface oil of the products. These observations are supported by a previous study on microstructural analysis of fried products [30]. The amount of oil absorbed into food after frying is highly dependent on surface oil. This is because the rigorous escape of steam from the food surface leads to the formation of crust which is characterised by tiny crevices that can allow the permeation of oil into the food core. During cooling, as the pressure gradient in the core of food drops, surface oil is absorbed through capillary forces into food through cracks in the crust [10]. Therefore, it is recommended that an appropriate draining technique be applied to remove surface oil, thus reducing oil uptake.

An increase in the SO content of fried batter was reported by Thanatuksorn et al. [23]. Contrary to this, we observed a higher SO content in the fried dough samples. This contradiction in the results could be due to (i) the difference in the surface oil collection method, where Thanatuksorn et al. [23] used the dipping method, and our product surface was washed to collect adhered oil. Dipping the sample could have caused the extraction of subsurface oil alongside adhered oil. (ii) Furthermore, a small sample size $(<10 \mathrm{~g})$ coupled with a prolonged frying time of $7 \mathrm{~min}$ increased crust-crumb ratio which meant more surface oil. From this study, it was observed that $\mathrm{SO}$ of fried dough was higher than fried batter. This can be explained as follows: (i) the dough had better structural integrity due to good pliability during kneading which led to gluten formation and gas retention, and (ii) the consistency of the batter caused more bubble formation which made the fried batter spongier (than its dough counterpart) and, as a result, could not retain oil on the food surface.

\subsection{Penetrated Surface Oil of Fried Products. Penetrated} surface oil (PSO) was significantly higher in fried batter samples. PSO was in the range $0.19-0.29 \mathrm{~g} / \mathrm{g}$ and $0.08-0.22 \mathrm{~g} /$ $\mathrm{g}$ in WBFB and WBFD, respectively (Figure 3 ), while OB samples ranged from 0.19 to $0.30 \mathrm{~g} / \mathrm{g}$ and 0.12 to $0.22 \mathrm{~g} / \mathrm{g}$ in OBFB (Figure 3(c)) and OBFD, respectively (Figure 3(d)). A significant decrease $(p<0.05)$ in PSO was observed in WB5 and WB20, while in fried dough, a reduction was only reported at WB10 and WB20 concentrations. For OBFB samples, a significant reduction from the control was found at OB10 and OB20 concentrations, while in OBFD samples, the reduction was seen as 15\%. Linear and interaction effects of the formulation and bran addition had a significant effect $(p<0.05)$ on PSO of magwinya. PSO is considered the most significant oil fraction because it accounts for a higher percentage of the total oil content of fried foods [8, 31]. PSO is the amount of oil absorbed in the crust microstructure, and this occurs toward the end of the frying $(10-20 \mathrm{sec})$ and cooling stage due to the change in temperature and core pressure gradient [31, 32].

Dehydration in fried cereal snack (magwinya) is most intense at the surface because of the high temperature $\left(180^{\circ} \mathrm{C}\right)$, which in turn leads to the formation of pores in the crust microstructure which are subsequently filled with oil 

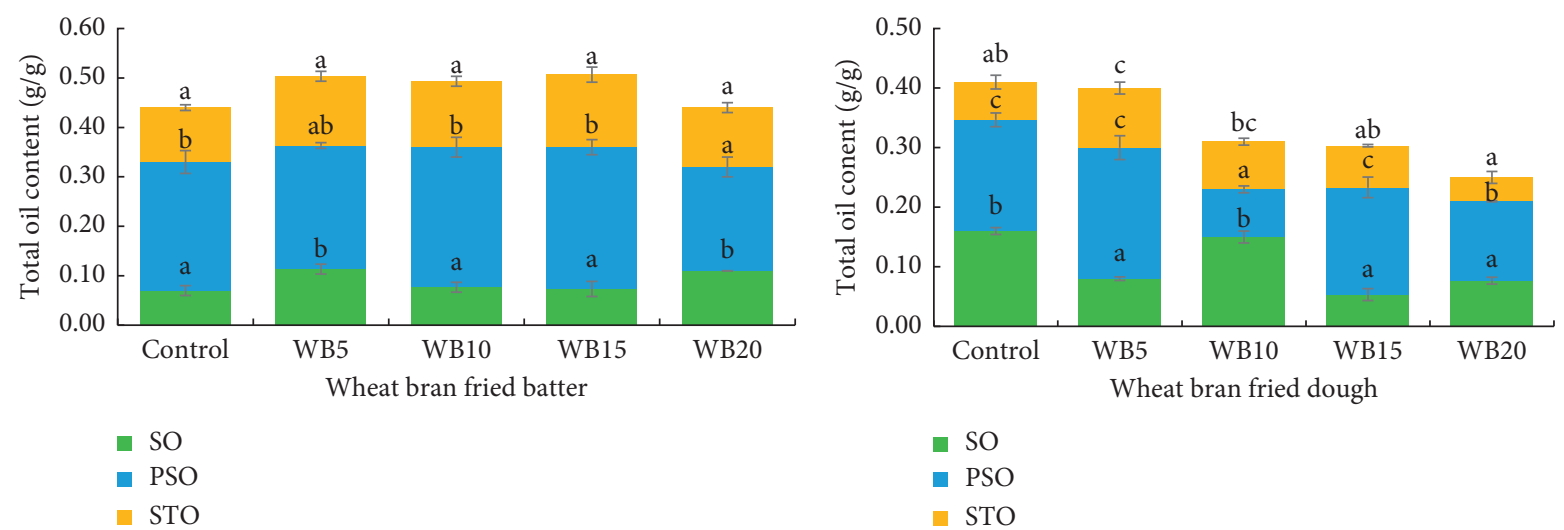

(a)
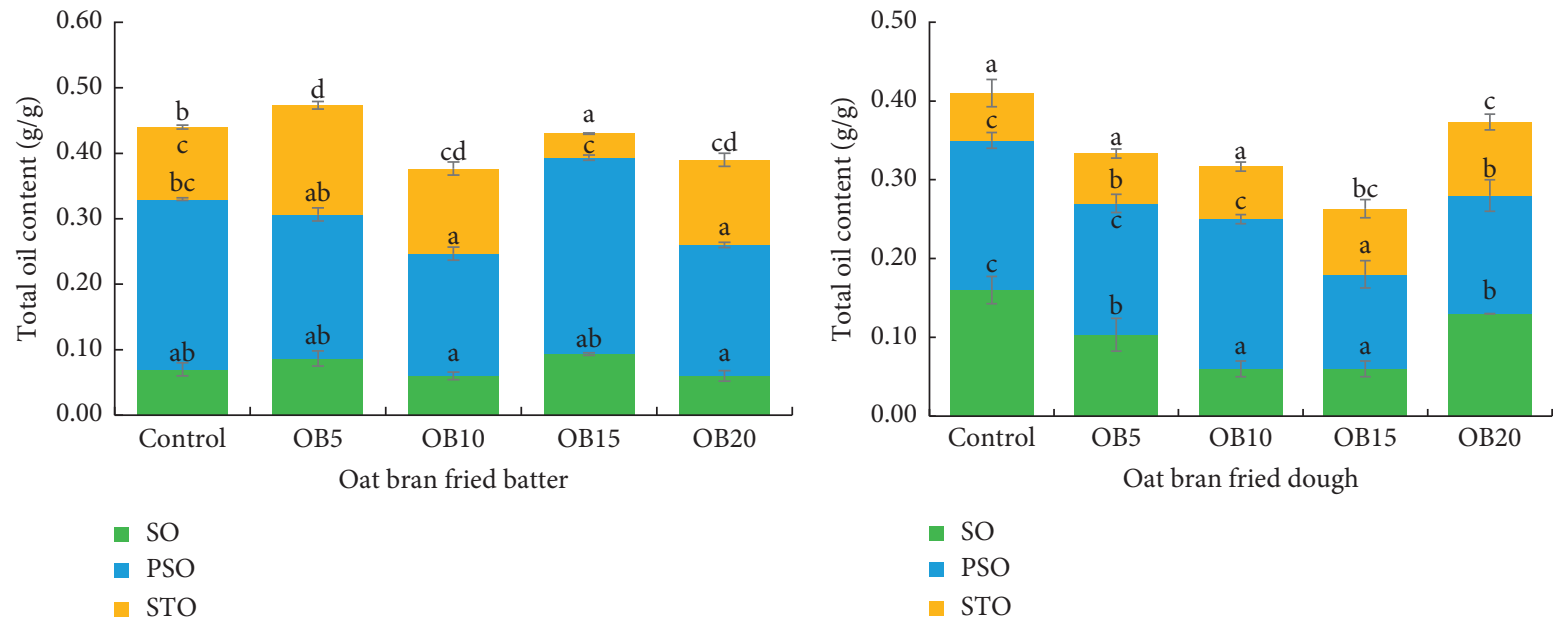

(c)

(d)

Figure 3: Total oil content (g/g dry basis) of (a) wheat bran (WB) fried batter, (b) WB fried dough, (c) oat bran (OB) fried batter, and (d) OB fried dough. SO: surface oil; PSO: penetrated surface oil; STO: structural oil. Values are the mean of four replicates. The error bar signifies standard deviation. The same bar colours with different superscripts showed significance $(p<0.05)$ using Duncan's multiple range test.

and/or air as the core temperature of the product decreases. Oil uptake in fried foods is a surface-related phenomenon that starts at the onset of cooling due to the competition between drainage and suction forces through which oil moves into the crust substructure. In the current study, the percentage of PSO was highest in all samples as confirmed in previous studies $[7,8,31]$. Another factor that could potentially contribute to increased PSO is the food surface roughness, increasing the cracks in the crust which increases the uptake of surface oil $[23,33]$.

3.4. Structural Oil of Fried Products. Structural oil (STO) corresponds to the amount of oil that is embedded in the core of food. STO was in the range $0.12-0.15 \mathrm{~g} / \mathrm{g}$ in WBFB and $0.04-0.11 \mathrm{~g} / \mathrm{g}$ in WBFD, while STO for OBFB ranged from 0.04 to $0.17 \mathrm{~g} / \mathrm{g}$, and STO for OBFD ranged from 0.04 to $0.09 \mathrm{~g} / \mathrm{g}$ (Figure 3). While the values of WB fried batter were close, those of OBFB were spread over a wide range, which could be attributed to the batter mass which was not as precise as the dough mass before frying. There was no significant difference $(p<0.05)$ among WBFB samples, while STO showed a significant increase in WBFD samples at $5-15 \%$ WB concentration and a decrease at WB20. Control STO of OBFB decreased from $0.11 \mathrm{~g} / \mathrm{g}$ to $0.04 \mathrm{~g} / \mathrm{g}$ in OB15. Generally, STO values were significantly higher in fried batter than in fried dough samples. This may be a function of the higher porosity in the fried batter which allows the free flow of oil into the food core [30]. STO was the lowest of the three fractions. The case is contrary in the potato products in which SO was the lowest oil fraction [8]. This reveals that oil distribution in fried foods differs from one product to the other. Unlike thin products such as potato chips that absorb most of oil during frying, magwinya is high-moisture and thick food, and thus, less oil is absorbed during frying and more during cooling [31, 32].

3.5. Total Oil Content of Cereal Fried Products. The sum of all oil fractions SO, PSO, and STO makes up the total oil content of the fried products. The total oil content of the samples was in the range $0.38-0.50 \mathrm{~g} / \mathrm{g}$ and $0.25-0.41 \mathrm{~g} / \mathrm{g}$ in WBFB and WBFD (Figure 3). Oil uptake reduction in WBFB was at $20 \%$ WB (Figure 3(a)), while in fried dough, a 
significant decrease $(p<0.05)$ at $10-20 \% \mathrm{WB}$ was observed (Figure 3(b)). The total oil content of OBFB samples was in the range $0.37-0.43 \mathrm{~g} / \mathrm{g}$ with a significant reduction in OB10 and OB20 and $0.26-0.41 \mathrm{~g} / \mathrm{g}$ in OBFD with consistent reduction with increments in $\mathrm{OB}$ concentration. Oil uptake in fried batter was higher than fried dough for both oat and wheat bran samples. This effect can be linked to the difference in initial moisture contents of both products. Regression analysis showed that the linear effect of the initial water content, bran addition, and interaction effect of both factors had a significant effect $(p<0.001)$ in wheat and oat bran samples. In the fried batter samples, there was a significant oil uptake reduction in OB samples, while WB samples showed less variation in the values reported. In the fried batter, an initial increase (OB5) in total oil uptake followed by a decrease was observed, while in OBFD, there was a steady increase from the control to OB15. A decrease in oil uptake from $0.43(\mathrm{~g} / \mathrm{g} \mathrm{db})$ in the control to $0.38(\mathrm{~g} / \mathrm{g} \mathrm{db})$ at $20 \mathrm{~g}$ OB inclusion in the fried dough was observed.

Yadav and Rajan [13] attributed the effect of oat fibre on oil uptake reduction in poori (an Indian fried flatbread) as a function of its significant water retention capacity which impeded moisture loss. Furthermore, the chemical composition of the fibre is less responsible for its oil binding capacity than the porosity of the fibre that serves as a storage space for water molecules when the fibre is hydrated, thereby reducing the oil binding property. Significant oil reduction effects of wheat and oat bran were observed in poori (an Indian deep-fried dough) at 3 and $11 \%$, respectively. Moisture loss-oil uptake effect in fried products confirmed that higher initial water content led to increased oil uptake due to the formation of pores by moisture evaporation which in turn creates pathways for oil uptake. The higher the moisture loss, the higher the oil uptake. Moisture loss-oil uptake effect in fried products as adequately reviewed by Ziaiifar et al. [10] revealed that the outflow of water from food leaves cracks for oil to occupy.

Factors that influence this mass transfer phenomenon in succession are (1) the initial water content of food, which in turn determines (2) the rate of water vaporisation over the frying period which directly impacts (3) crust thermal conductivity and (4) crust texture and porosity. In terms of the effect of the initial water content, Gazmuri and Bouchon [1] reported no significant difference in oil uptake of the fried dough matrix with 38 and $44 \%$ of water content; nonetheless, they found a relevant difference when the amount of gluten in the products was considered. This "no significant effect may be caused by the small difference (6\%) in the water content of the compared dough matrices." In this study, a wide difference (35\%) in water contents of dough and batter could account for the higher oil uptake in fried batter samples. Hence, to control the crust and crumb texture of fried foods, the water retention capacity of the dough, initial water content, and moisture content after frying are important.

Frying is a heat and mass transfer phenomenon. Heat transferred from oil to the food culminates in mass transfer-moisture evaporation and oil influx into food. Volume expansion and heat transfer occur through a combination of convective (from oil to food) and conductive (within food) forces. The rate of heat transfer during frying is affected by bubble movement that occurs and may reduce when there is maximum or vigorous water loss which causes a resistance to heat transfer $[10,34]$. In this current study, fried batter had higher bubble movement than fried dough, which may be attributed to the high moisture content of fried batter and the high thermal conductivity coefficient of fried dough as higher heat transfer coefficients have been reported in the absence of vapour bubbling. Upon immersion in hot oil, the fried batter sank to the bottom of oil and floated under $10 \mathrm{sec}$, whereas the fried dough floated almost instantaneously. This variation in floatation time can be linked to water differences in the formulation and density of the products [35]. As water is lost during frying, the product volume increases, and the density reduces, which makes the fried products float. Floatation results from heat conversion of water to steam which causes a pressure that pushes against the food crust, and in turn, volume expansion puffiness occurs which causes food to rise to the surface of oil. Floatation may, as well, contribute to mass transfer differences in the products, thereby resulting in thermal conductivity variation at the top and bottom crust of the product. To combat this variation, the product was constantly turned every thirty seconds during frying.

3.6. Correlation of Oil Fractions, Weight, and Moisture Loss. Pearson's correlation examined relationships among the properties of fried snacks as presented in Table 1. In OB fried batter, a negative correlation was reported between weight and moisture loss, meaning that products with higher weight values did not lose much moisture. There was a negative significant correlation $(p<0.01)$ between PSO and STO, implying that higher PSO led to lower STO, and vice versa. Similarly, SO correlated positively with total oil uptake. This buttresses the point that oil absorbed into the sample during cooling depends on oil on the product surface. There was no significant correlation between weight and oil fractions because the weights of fried dough were uniform. Moisture loss correlated negatively with various oil fractions except STO in fried dough samples (Table 1).

Although moisture loss has been reported to play a role in oil absorption, the negative correlation in this study may be explained by the effect of bran addition which impacts moisture loss and, in turn, oil content. Surface oil positively influenced PSO and total oil content, while PSO negatively correlated with STO, meaning that the higher the PSO, the lower the STO, and vice versa. This implies that these oil fractions are not uniformly distributed in fried cereal snacks (magwinya). Weight of WB fried batter correlated positively with moisture loss and PSO. The three oil fractions all correlated positively $(p<0.01)$ with the total oil content (Table 2). In fried dough, weight correlated positively $(p<0.01)$ to STO and total oil content. Moisture loss correlated positively to PSO. Structural oil correlated positively with PSO, implying that an increase in one led to an increase in the other. The total oil content had a positive significant relationship with weight, PSO, and STO. 
TABLE 1: Pearson's correlation for the oat bran- (OB-) enriched fried product.

\begin{tabular}{|c|c|c|c|c|c|}
\hline & Weight & Moisture loss & Surface oil & PSO & Structural oil \\
\hline \multicolumn{6}{|l|}{ OB fried batter } \\
\hline Moisture loss & $-0.530^{*}$ & & & & \\
\hline Surface oil (SO) & 0.062 & -0.257 & & & \\
\hline Penetrated SO (PSO) & 0.177 & 0.149 & 0.367 & & \\
\hline Structural oil & -0.072 & -0.239 & -0.205 & $-0.824^{* *}$ & \\
\hline Total oil content & 0.392 & -0.325 & $0.651^{* *}$ & 0.402 & 0.108 \\
\hline \multicolumn{6}{|l|}{ OB fried dough } \\
\hline Moisture loss & -0.205 & & & & \\
\hline $\mathrm{SO}$ & 0.099 & $-0.817^{* *}$ & & & \\
\hline PSO & 0.346 & $-0.443^{*}$ & $0.512^{*}$ & & \\
\hline Structural oil & -0.212 & 0.169 & -0.094 & $-0.728^{* *}$ & \\
\hline Total oil content & 0.424 & $-0.679^{* *}$ & $0.789^{* *}$ & $0.538^{*}$ & -0.079 \\
\hline
\end{tabular}

${ }^{* *}$ Correlation is significant at the 0.01 level. ${ }^{*}$ Correlation is significant at the 0.05 level.

TABLE 2: Pearson's correlation for the wheat bran- (WB-) enriched fried product.

\begin{tabular}{|c|c|c|c|c|c|}
\hline & Weight & Moisture loss & Surface oil & PSO & Structural oil \\
\hline \multicolumn{6}{|l|}{ WB fried batter } \\
\hline Moisture loss & $0.496^{*}$ & & & & \\
\hline Surface oil (SO) & 0.04 & 0.129 & & & \\
\hline Penetrated SO (PSO) & $0.521^{*}$ & 0.278 & -0.044 & & \\
\hline Structural oil & 0.35 & 0.264 & $0.604^{* *}$ & $0.698^{* *}$ & \\
\hline Total oil content & 0.35 & 0.264 & $0.614^{* *}$ & $0.624^{* *}$ & $1.000^{* *}$ \\
\hline \multicolumn{6}{|l|}{ WB fried dough } \\
\hline Moisture loss & 0.335 & & & & \\
\hline $\mathrm{SO}$ & -0.021 & -0.287 & & & \\
\hline PSO & 0.263 & $0.520^{*}$ & $-0.730^{* *}$ & & \\
\hline Structural oil & $0.599^{* *}$ & 0.065 & -0.235 & $0.438^{*}$ & \\
\hline Total oil content & $0.560^{* *}$ & 0.266 & 0.107 & $0.529^{*}$ & $0.713^{* *}$ \\
\hline
\end{tabular}

${ }^{* *}$ Correlation is significant at the 0.01 level. ${ }^{*}$ Correlation is significant at the 0.05 level.

\section{Conclusions}

The inclusion of oat bran (OB) in fried dough from 5 to $20 \%$ and fried batter at $10 \%$ reduced the total oil content. Significant oil uptake reduction in wheat bran (WB) fried dough (WBD) occurred at $10-20 \%$. Oil distribution in fried dough products (magwinya) revealed interesting results as follows: penetrated surface oil (PSO) contributed mostly to the total oil content of all the fried products at $46 \%$ for WBD and $53 \%$ and $57 \%$ for WB and $\mathrm{OB}$ fried batter, respectively. Furthermore, oil distribution varied based on low- or high-moisture formulation. In fried batter (high moisture), the ranking is as follows: $\mathrm{PSO}>$ structural oil (STO) > surface oil (SO), while in the fried dough (low moisture) products, the ranking is $\mathrm{PSO}>\mathrm{SO}>\mathrm{STO}$. Results confirm that oil uptake in the fried dough-based product (magwinya) is a surface-related phenomenon. However, the distribution of the oil fractions is moisture dependent.

\section{Data Availability}

The data used to support the findings of this study are included within the article.

\section{Conflicts of Interest}

The authors declare no conflicts of interest regarding the publication of this paper.

\section{Acknowledgments}

This work was funded by the Directorate of Research and Innovation of Univen, South Africa (SA) to OOO (SARDF/ 17/FST/03) and the National Research Foundation, Centre of Excellence in Food Security SMART Foods Project (ID: 160201).

\section{References}

[1] A. M. Gazmuri and P. Bouchon, "Analysis of wheat gluten and starch matrices during deep-fat frying," Food Chemistry, vol. 115, no. 3, pp. 999-1005, 2009.

[2] P. Bouchon, "Chapter 5 understanding oil absorption during deep-fat frying," Advances in Food \& Nutrition Research, vol. 57, pp. 209-234, 2009.

[3] R. B. Suárez, L. A. Campañone, M. A. García, and N. E. Zaritzky, "Comparison of the deep frying process in coated and uncoated dough systems," Journal of Food Engineering, vol. 84, no. 3, pp. 383-393, 2008.

[4] E. J. Pinthus, P. Weinberg, and I. S. Saguy, "Criterion for oil uptake during deep-fat frying," Journal of Food Science, vol. 58, no. 1, pp. 204-205, 1993.

[5] P. Bouchon and J. M. Aguilera, "Microstructural analysis of frying potatoes," International Journal of Food Science and Technology, vol. 36, no. 6, pp. 669-676, 2001.

[6] S. Lalam, J. S. Sandhu, P. S. Takhar, L. D. Thompson, and C. Alvarado, "Experimental study on transport mechanisms during deep fat frying of chicken nuggets," Lebensmittel- 
Wissenschaft und -Technologie- Food Science and Technology, vol. 50, no. 1, pp. 110-119, 2013.

[7] G. Ufheil and F. Escher, "Dynamics of oil uptake during deepfat frying of potato slices," Lebensmittel-Wissenschaft undTechnologie-Food Science and Technology, vol. 29, no. 7, pp. 640-644, 1996.

[8] P. B. Ouchon, J. M. Aguilera, and D. L. Pyle, "Structure oilabsorption relationships during deep-fat frying," Journal of Food Science, vol. 68, no. 9, pp. 2711-2716, 2003.

[9] M. W. J. Noort, D. van Haaster, Y. Hemery, H. A. Schols, and R. J. Hamer, "The effect of particle size of wheat bran fractions on bread quality-evidence for fibre-protein interactions," Journal of Cereal Science, vol. 52, no. 1, pp. 59-64, 2010.

[10] A. M. Ziaiifar, N. Achir, F. Courtois, I. Trezzani, and G. Trystram, "Review of mechanisms, conditions, and factors involved in the oil uptake phenomenon during the deep-fat frying process," International Journal of Food Science and Technology, vol. 43, no. 8, pp. 1410-1423, 2008.

[11] R. Xu, "Oat fibre: overview on their main biological properties," European Food Research and Technology, vol. 234, no. 4, pp. 563-569, 2012.

[12] O. O. Onipe, A. I. O. Jideani, and D. Beswa, "Composition and functionality of wheat bran and its application in some cereal food products," International Journal of Food Science and Technology, vol. 50, no. 12, pp. 2509-2518, 2015.

[13] D. N. Yadav and A. Rajan, "Fibres as an additive for oil reduction in deep fat fried poori," Journal of Food Science \& Technology, vol. 49, no. 6, pp. 767-773, 2012.

[14] B.-K. Kim, Y.-G. Chun, A.-R. Cho, and D.-J. Park, "Reduction in fat uptake of doughnut by microparticulated wheat bran," International Journal of Food Sciences \& Nutrition, vol. 63, no. 8, pp. 987-995, 2012.

[15] V. Dueik, O. Sobukola, and P. Bouchon, "Development of low-fat gluten and starch fried matrices with high fiber content," Lebensmittel-Wissenschaft und-Technologie-Food Science and Technology, vol. 59, no. 1, pp. 6-11, 2014.

[16] O. O. Onipe, D. Beswa, V. A. Jideani, and A. I. O. Jideani, "Development of a low-fat, high-fibre snack: effect of bran particle sizes and processing conditions," Heliyon, vol. 5, no. 3, Article ID e01364, 2019.

[17] F. F. Shih, K. W. Daigle, and E. L. Clawson, "Development of low oil-uptake donuts," Journal of Food Science, vol. 66, no. 1, pp. 141-144, 2001.

[18] P. Yazdanseta, B. G. Tarzi, and M. Gharachorloo, "Effect of some hydrocolloids on reducing oil uptake and quality factors of fermented doughnuts," Journal of Biodiversity and Environmental Sciences, vol. 6, pp. 233-241, 2015.

[19] S. Hemdane, P. J. Jacobs, E. Dornez, J. Verspreet, J. A. Delcour, and C. M. Courtin, "Wheat (Triticum aestivum L.) bran in bread making: a critical review," Comprehensive Reviews in Food Science and Food Safety, vol. 15, no. 1, pp. 28-42, 2016.

[20] O. Kwinda, O. O. Onipe, and A. I. O. Jideani, "The effect of oat bran and psyllium husk fibre on oil reduction and some physicochemical properties of magwinya-a deep-fried dough," CyTA-Journal of Food, vol. 16, no. 1, pp. 247-254, 2018.

[21] O. O. Onipe, D. Beswa, V. A. Jideani, and A. I. O. Jideani, "Optimization of processing conditions for oil reduction of magwinya (a deep-fried cereal dough)," African Journal of Science, Technology, Innovation and Development, vol. 10, no. 2, pp. 209-218, 2018.

[22] M. Durán, F. Pedreschi, P. Moyano, and E. Troncoso, "Oil partition in pre-treated potato slices during frying and cooling," Journal of Food Engineering, vol. 81, no. 1, pp. 257-265, 2007.

[23] P. Thanatuksorn, C. Pradistsuwana, P. Jantawat, and T. Suzuki, "Effect of surface roughness on post-frying oil absorption in wheat flour and water food model," Journal of the Science of Food and Agriculture, vol. 85, no. 15, pp. 2574-2580, 2005.

[24] G. Cruz, J. P. Cruz-Tirado, K. Delgado et al., "Impact of predrying and frying time on physical properties and sensorial acceptability of fried potato chips," Journal of Food Science \& Technology, vol. 55, no. 1, pp. 138-144, 2018.

[25] American Association of Cereal Chemists International, Approved Methods of the AACC, American Association of Cereal Chemists International, St. Paul, Minnesota, USA, 11th edition, 2000.

[26] Z. S. Zolfaghari, M. Mohebbi, and M. H. H. Khodaparast, "Quality changes of donuts as influenced by leavening agent and hydrocolloid coatings," Journal of Food Processing and Preservation, vol. 37, no. 1, pp. 34-45, 2013.

[27] S. Budžaki and B. Šeruga, "Moisture loss and oil uptake during deep-fat frying of "Kroštula" dough," European Food Research and Technology, vol. 220, pp. 90-95, 2005.

[28] O. O. Onipe, D. Beswa, and A. I. O. Jideani, "Effect of size reduction on colour, hydration and rheological properties of wheat bran," Food Science and Technology, vol. 37, no. 3, pp. 389-396, 2017.

[29] C.-S. Chen, C.-Y. Chang, and C.-J. Hsieh, "Improving the texture and colour of fried products, frying," in Frying: Improving Quality, J. B. Rossell, Ed., Woodhead Publishing, Boca Raton, FL, USA, pp. 337-358, 2001.

[30] O. O. Onipe, D. Beswa, and A. I. O. Jideani, "Confocal laser scanning microscopy and image analysis for elucidating crumb and crust microstructure of bran-enriched South African fried dough and batter," Foods, vol. 9, p. 605, 2020.

[31] F. Pedreschi, C. Cocio, P. Moyano, and E. Troncoso, "Oil distribution in potato slices during frying," Journal of Food Engineering, vol. 87, no. 2, pp. 200-212, 2008.

[32] T. Zhang, J. Li, Z. Ding, and L. Fan, "Effects of initial moisture content on the oil absorption behavior of potato chips during frying process," Food and Bioprocess Technology, vol. 9, no. 2, pp. 331-340, 2016.

[33] M. C. Moreno, C. A. Brown, and P. Bouchon, "Effect of food surface roughness on oil uptake by deep-fat fried products," Journal of Food Engineering, vol. 101, no. 2, pp. 179-186, 2010.

[34] A. Alvis, C. Vélez, M. Rada-Mendoza, M. Villamiel, and H. S. Villada, "Heat transfer coefficient during deep-fat frying," Food Control, vol. 20, no. 4, pp. 321-325, 2009.

[35] A. Ghaitaranpour, M. Elahi, M. N. Nagafi, and M. Mohebbi, "Effect of storage at ambient temperature on quality of doughnut," Agricultural Advances, vol. 2, pp. 139-145, 2013. 